\title{
Can a disabled person be the best person for the job? Disability and the merit principle in the Public Service
}

\author{
Robyn Hunt*
}

This paper explores the assumptions underlying the merit principle in relation to disabled people in the New Zealand Public Service. It suggests a view of merit which is more compatible with affirmative action strategies and it discusses some of the implications for EEO disability.

\section{Introduction}

Since the Statement of government employing authorities 1984 listed disabled people alongside other groups disadvantaged in the labour market, this group has featured with them in the provision of equal employment opportunities (EEO) programmes in the Public Service and elsewhere: that is, employment on merit in the open labour market. With the passage of the State Sector Act 1988, people with disabilities became 1 of the 4 designated groups for whom EEO plans and programmes became mandatory in the core Public Service.

The development of EEO has coincided with major changes in the New Zealand Public Service and the way it operates. These changes have resulted in a smaller, decentralized and more specialized Public Service, with a stronger emphasis on performance and a demand for higher skill levels among public servants. These changes have had some implications for the employment of people with disabilities.

In considering the relationship between disability and the merit principle, it must be acknowledged that disability, unlike race or gender, can be relevant to performance, and that there is room for argument about how and where this factor has impact. This aspect of disability is often over-estimated at the expense of other considerations, especially as there is a lack of vocational assessment standards in New Zealand. This grey area might not cause such debate and confusion if merit were better understood and defined more broadly. When a person is clearly unable to compete on merit, the State Services Commission operates a supported employment programme, Mainstream, formerly the Scheme for the Employment of the Disabled. While this programme is not an EEO programme, because those on the programme are unable to compete on merit, it may, for some, be a stepping-stone to open competition. This paper considers open employment on merit and argues for its wider application, offering some point of discussion to begin the process.

Although this paper focuses on the Public Service, the same principles can be applied elsewhere.

* Workbridge Inc., Brandon Street, Wellington. 


\section{The merit principle}

"The concept of merit refers to a relationship between a person's qualities and those required for performance in particular positions" (Burton, 1988, p.1). The dictionary definition includes terms such as "value" and "worth". Section 60 of the State Sector Act states "A chief executive, in making an appointment under the Act, shall give preference to the person who is best suited to the position". The Act does not elaborate on the qualities which might have to be taken into account in making that appointment. Section 28 of the now repealed State Services Act 1962, stated:

the merit of an officer ... shall be determined by:

- work experience and competence shown in performance of duties previously carried out by him (sic); and

- personal qualities, characteristics and attributes relevant to the position to be filled; and

- relevant education or other qualifications.

In the absence of any more recently codified standard, it is reasonable to assume that these factors are still considered by Public Service employers when appointing staff. The best person for the job would therefore be the person with the best qualifications, experience and personal qualities.

One way in which merit has been expanded is the wider acceptance that there may be other types of experience relevant to the successful performance of duties in a particular position. Community and child-rearing experience are increasingly seen as being valuable and relevant in terms of skills required to fill a position.

Another description of the merit principle states that:

the procedures are applied to all vacancies. Anyone can apply for the position; the procedures constitute comparative assessment of applicants, and the criteria for choosing between applicants is merit. The position is filled on the basis of the applicant chosen to perform the duties of the position better than other applicants and closest to the optimum level of job performance (Ziller, 1985).

(Merit) concerns only characteristics of people that are relevant to task performance - that is, how well they perform certain tasks. (In practice, of course, we know that many of the things that count as merit may bear little or no relation to the potential or actual job performance.) (Edwards, 1990, p.28).

In any consideration of merit it has to be remembered that skills are transferable and can be upgraded. Otherwise all considerations of merit would be looked at in a narrow present-tense way.

\section{Merit in present practice}

Most of the foregoing gives the impression that the merit principle is some kind of impartial and objective "gold standard". This is not so. "The determination of the best person for the job is made with reference to factors over and above the skill and knowledge requirements for performance in a position" (Burton, 1988, p.2). It should be acknowledged that it is very difficult to eliminate bias from any system. This acknowledgement alone would be an improvement on the way merit works currently for people with disabilities. 
The kinds of qualifications and experience valued and sought may represent a particular bias. An example might be the listing of a tertiary qualification as necessary for a particular job. However, an analysis of the skills needed for that particular job might show that the qualification was not necessary. Thus an applicant might have the necessary skills but not have a tertiary qualification.

Ability itself is difficult to define, identify and measure, although it is interesting to note that the 1989 Results of a survey for people with a disability in the Public Service (Gray and Burns, 1989) found that "the public servants responding to the survey had a high level of educational attainment" and that "the figures suggest that among this sample, having a disability was no barrier to educational achievement. Among those with postgraduate degrees were several with severe disabilities, including quadriplegia, muscular dystrophy, multiple sclerosis and profound deafness" (Gray and Burns, 1989, p.9). Even if academic qualifications are necessary, they can be found among people with disabilities.

This would indicate that a perceived lack of merit on the part of the group of people with disabilities in the Public Service could not necessarily be based on lack of educational qualifications for the job. But, the area of "personal qualities, characteristics and attributes relevant to the position to be filled", does leave room for assumptions and subjective judgements.

There have been some in the Public Service who believe that people with disabilities cannot compete on merit at all. The 1986 Review of the employment of disabled persons in the Public Service (Stone, 1986) found a department which was opposed to employing people with disabilities:

... we must now work to a budget which includes labour, equipment and operating expenses. Departments operating under this constraint must then act so as to optimise their expenditure accordingly. There is now no incentive for our department to employ a disabled person as they now become a cost which must be included in this budget. A disabled person is now required to compete on the free market for positions within the department (Stone, 1986, Appendix $15)$.

The basic assumption here is that a person with a disability cannot be a fully productive member of the team and will be a cost to an employer. But, there is a cost factor involved with any employee. Non-disabled employees are fortunate in never having had their contributions costed in a similar way.

The assumption of extra cost is one of the commonest assumptions which affect merit-based selection and promotion of people with disabilities. It is a reflection of our pioneering past when work was largely manual, and being fit to work and an "able-bodied worker" were perhaps valid characteristics. It also shows a lack of knowledge about the wide range of disabilities.

In the past, people with disabilities were often channelled into the kind of manual work which is fast disappearing. Judgements are subjective and still based on outmoded assumptions about the capacity of disabled people to perform in a range of different jobs beyond those requiring a lower level of skill.

The alleged correlation between disability and a lack of productivity has arisen from the "functional limitation" paradigm outlined elsewhere in this symposium. Gray and Burns (1989) reported:

The most frequent complaint in relation to employment was that the interviewer paid far too much attention to the perceived drawbacks of disabilities and too little to the skills and positive attributes of applicants. Other interviewers projected their often ill-informed ideas about particular conditions onto applicants, whether or not it was appropriate (Gray and Burns, 1989, p.29). 
A male with diabetes recounted how interviewers' experience with another person with the same condition had coloured their judgement about him and how it had taken him several years to establish himself as an individual. Stereotyping and labelling had obviously got in the way of consideration of his merit.

There is little doubt that disability has been used for screening out potential employees on application forms, and that employers often cannot accurately evaluate the capabilities of disabled applicants. "One human resource manager thought that some questions were necessary because he believed, erroneously that a person with a vision impairment could not use a computer screen" (State Services Commission, 1990, p.12). Lack of knowledge and assumptions about the disabled would preclude any merit considerations.

Characteristics which affect such decisions are based on physical appearance and perceptions of unusual or different behaviour, such as the old fear of epileptic seizures. Physical difference is frowned on in Western society where "corporate culture" as adopted by the Public Service sets standards of appearance which have been fostered by decades of advertising and media reinforcement. Consequently, there has been some resistance to employing people with disabilities in areas where they may have contact with the public.

While Public Service employers may not be as overt as the interviewer of a potential social worker who told her that her facial paralysis would "frighten the clients", there is evidence of such values in the Public Service, and many applicants feel that they must minimize their disabilities at interviews because of the negative aspect of such personal characteristics.

Pervasive workplace cultures also result in the appointment of people most like those who are already there, making it difficult for disabled people (as well as other unrepresented groups) to fit into "non-traditional" areas. Their personal characteristic, that of being disabled, may make interviewers feel uncomfortable and therefore counteract any merit considerations.

Such discriminatory behaviour is evidence of a lack of value ascribed to particular life experiences. For example, our social worker applicant's experience of disability may well have been of value to the discriminatory employer.

Disability experience is not valued in the New Zealand Public Service. While experience of women, Maori and Pacific Island people has been recognized as being of value, at least in areas where policy-making has direct impact on those groups, and senior policy decision-makers usually come from those groups (it seems unthinkable that there should be a male chief executive of the Ministry of Women's Affairs, or Pakeha chief executive of Manatu Maori), yet those who take senior policy roles in the area of disability do not share the life experience of people with disabilities.

Like other groups, however, the work performed by people with disabilities is often under-valued, in the same way as women's work is under-valued. Burton quotes an American study:

Men and women tend to rate men's work more highly than women's identical performance. When the participants are asked to explain the causes of successful performances of men and women, they attribute the male's performance to his ability and the female's to the greater effort she put into the task (Burton, 1988, p.3).

An almost identical situation occurred in relation to a performance appraisal in a New Zealand government department:

... in one performance appraisal for a public servant with a disability, the supervisor recognised the employee's ability. However this was overruled by a manager who attributed the staff member's high performance to "working hard because of his disability" (State Services Commission, 1989, p.15). 
This kind of judgement affects opportunities for advancement, because ability is more likely to be rewarded with promotion, but greater effort is not seen as a reliable indicator of future performance.

While performance appraisal systems attempt to be objective and unbiased, they do not function in isolation from judgements made concerning the individual's merit in the workplace. "Informal judgements about people are made all the time, sometimes based on hearsay, misperception and power group considerations" (Waldron, 1988).

Performance appraisals are therefore not always focussed clearly on the basis of the component tasks which make up the job, and the required outcomes of work set against objectives, even if these objectives were set fairly in the first place.

Making a comparison between groups which experience similar problems in relation to merit is a reminder that the merit principle as it currently exists can work against all the designated groups, even though the yardsticks may work in different ways for different groups, or work in similar ways, as illustrated above. An example of a different kind of yardstick for a different group might be assumptions about language skills and social interaction of ethnic-minority people. However, whatever the group and whatever the yardstick used, the effect of the merit principle is the same for most groups: disadvantage.

The processes involving judgements of merit affect the ability and capacity of an individual to advance. Experience at work, the opportunities provided, the expectations of others, and others' attitudes towards them, have a significant effect on their aspirations and competencies. Merit is an outcome of organizational processes. This paper has outlined but a few of these processes. Access to opportunities allows merit to develop and flourish.

\section{A broader definition of merit}

To ensure a better use of valuable human resources, both existing and potential, a more comprehensive definition of merit needs to be developed. This process might begin with an open acknowledgement of the biases which currently affect the operation of the merit principle. While eliminating bias may be a difficult and long-term exercise, this acknowledgement would be an important first step in the process which would culminate in a tighter but broader definition.

The argument for diversity was touched on earlier. Where policy is being made, or services are being delivered to people with disabilities, a recognition that disabled people might be employed in these areas has been slower than similar developments for other groups. People with disabilities are still being denied opportunity even in their own area of expertise.

Both here and overseas, the broadening of merit has occurred to meet these needs for other groups, with some success. Also referred to earlier was the broadening of merit by including transferable skills gained in community and voluntary work. Women's domestic experience while bringing up their families is also beginning to be valued in this way. This has not led to a decline in standards in the New Zealand Public Service.

Diversity demands that we create a new skills "menu". When an employer has defined a skill as needed, there needs to be a menu of places to look for that skill. For example, if seeking the skill of adaptability, the menu for searching could include previous work experience; running a community centre or becoming disabled at some point in a person's life and then managing that change would be evidence of the skill required. Not to do so would mean overlooking merit.

To make the merit principle fit more easily does not necessarily mean standards will decline as a consequence, as some people have feared. They have argued that challenges to mandatory qualifications, for example, will create problems with the quality of work. But a closer look at the actual work to be done and a matching of skills and experience 
can result in the same high standard. (Qualifications which are a legal requirement, such as medical or legal, cannot, of course, be circumvented.)

But there is evidence that some qualities which are highly valued in some people are not even looked for in others, simply because it has never occurred to anyone to do so. This is particularly true for people with disabilities, for whom prevailing social attitudes obscure some important qualities.

It is important that the new human resource technology such as psychological testing or performance appraisal does not discriminate in the way it illuminates merit. There is a tendency to "clone" because of the structure of the instrument itself and the way it is used. For example, some people with a disability can be discounted if the exercise includes paper and pencil or speed tests. Testers may not even have an accessible venue - as in the case of some consultants doing psychological testing. New instruments to help measure merit need to be fair.

People with disabilities have developed skills which have been largely overlooked. Change management skills have been increasingly valued during the 1980 s and such skills have been an everyday part of the lives of many disabled people for so long that they do not always recognize and value them for what they are. Yet, for many, a fluctuating condition such as asthma, arthritis or mood swings must be carefully watched and managed to prevent recurrences or worsening. Strategies must be developed when unavoidable change does occur. Many people, such as those with paraplegia, deal successfully with major long-term change. These techniques are not generally recognized and valued in the workplace.

To get to work at all can be a major logistical exercise for some disabled people. They may not have easy access to transport and the process may involve sophisticated techniques such as orientation and mobility, practised expertly by blind workers. Their lives are carefully organized and structured around their working day. Getting started in the morning may require great physical effort. It may require organizing other people, such as attendant carers and taxi drivers to meet their needs. Yet others, particularly women with disabilities, may have family duties in addition to those of the workplace. Such valuable organizational skills are seldom sought or valued.

It is therefore possible to change the way people with disabilities, along with other groups, can be judged on their merit. While it might seem a radical move to take supposedly negative qualities associated with a concept such as disability and turn them around towards a positive view, these are changing times and the merit principle must operate in a way appropriate to the modern Public Service.

\section{Implications for EEO disability}

It would be reasonable to assume that the escape from the effect of negative value judgements and the self-fulfilling prophecies which result from continued low selfexpectation would benefit both disabled people and the Public Service at large.

If a more comprehensive view of merit were taken, disabled public servants and their employers would reap the benefits of training and development. In times of restructuring they would not, along with other designated groups, be disproportionately represented in redundancy figures. Their contribution would be greater and that greater contribution would be recognized and valued, leading to higher levels of job satisfaction and productivity. Policy-making and service delivery for the disability community would be of a higher standard and the Public Service would become more diverse and better represent and serve the wider community. 


\section{Conclusion}

Merit should not be seen as one way or one yardstick where there is an obsession with treating everyone the same or evaluating in the same way. It is about knowing what it is you are looking for, and being prepared to search in different places to find it. There needs to be an understanding of the different ways skills can present themselves.

I have shown that it is possible to challenge the way the merit principle has operated for people with disabilities. Its results have been unfair and wasteful. The way merit has been viewed has not kept pace with changes in the Public Service. The time has come for the traditional narrow view of merit to change and broaden to encompass the talents, skills and abilities of a wider range of people. It is hoped that this paper might be a first step in the process of redefining merit in relation to disabled people in the Public Service.

\section{References}

Burton, C. (1988) Redefining merit. Sydney, Affirmative Action Agency (Occasional Paper No. 2).

Edwards, J. (1990) Affirmative action culture and US equal opportunity practice. Equal opportunity review No. 34 Manchester, Equal Opportunities Commission.

Gray, A. and Burns, J.A. (1989) A survey for people with disabilities in the Public Service. Wellington, State Services Commission.

State Services Commission (1990) The invisible minority: a report of the Policy Development Working Group on the Employment of People with Disabilities. Wellington.

Stone, J. (1986) Review of the employment of disabled persons in the Public Service. Wellington, State Services Commission.

Waldron, L.A. (1988) The dilemma of merit pay in the public sector. Melbourne, Human Resources Management Australia.

Ziller (1985) Quoted in D. Adams Equal employment opportunity and moral reasoning in policy analysis. Hobart, University of Tasmania. 